\title{
Memoria, palabra y acción: La historia patria, un saber para el sentimiento ${ }^{1}$
}

\section{Resumen}

Este artículo que proponemos intentará explorar las relaciones entre historia y retórica en una modalidad textual particular: la denominada historia patria, cuyo origen se puede rastrear en Colombia a partir de 1850 con el Compendio de la historia de la Nueva Granada, de José Antonio de Plaza; el Catecismo republicano, de Cerbeleón Pinzón y, posteriormente, con los libros escritos por José Joaquín Borda (Historia de Colombia contada a los niños) y José María Quijano Otero (Compendio de historia patria). Queremos destacar que la historia patria no es equivalente a la historia nacional toda vez que su carácter de compendio o resumen define no solo unas prácticas específicas de la escritura histórica sino que además sigue unida a los géneros literarios establecidos por la retórica y que su carácter oralizable orienta las potencialidades de los libros y de sus contenidos, más en relación con la memoria, que con los límites de un saber objetivo y reflexivo.

Palabras Clave: Colombia, historia, nación, memoria, oralidad.

Referencia para citar este artículo: CARDONA ZULUAGA, Alba Patricia (2016). "Memoria, palabra y acción: La historia patria, un saber para el sentimiento". En Anuario de Historia Regional y de las Fronteras. 21 (2). pp. 19-45.

\begin{abstract}
Alba Patricia Cardona Zuluaga: Doctora en Historia, Universidad de los Andes. Magíster en Historia, Universidad Nacional. Profesora titular del Departamento de Humanidades, Universidad Eafit de Medellín y adscrita al grupo de investigación en Filosofía, Hermenéutica y Narrativas, de la misma institución. Correo electrónico: azuluaga@eafit.edu.co.
\end{abstract}

\footnotetext{
${ }^{1}$ Este artículo se deriva de la investigación Retórica y géneros narrativos en Colombia, segunda mitad del siglo XIX, financiada por la Universidad Eafit.
} 


\title{
Memory, Words and Actions: Homeland History, Knowledge for Awakening Feelings
}

\begin{abstract}
The article we propose attempts to explore the relationship between history and rhetoric in a particular textual form: the so-called homeland history, whose origins can be explored in Colombia from 1850 on the Compendium of the history of New Granada by Jose Antonio Plaza, on the Republican Catechism by Cerbeleon Pinzon and later, in the books written by Jose Joaquin Borda (History of Colombia told for children) and Jose Maria Quijano Otero (Compendium of Homeland History). We want to note that homeland history is not exactly the same as national history, its nature as a digest or summary defines not only some specific practices of historical writing, but it also shows it attachment to the literary genres established by rhetoric; and its "orality" defines the potential of its books and their contents, more in relation to memory than to the limits of an objective and thoughtful knowledge.
\end{abstract}

Keywords: Colombia, History, Nation, Memory, Orality.

\section{Memória, palavra e ação: A história pátria, um saber para o sentimento}

\section{Resumo}

$O$ artigo que propomos tentará explorar as relações entre história e retórica em uma modalidade textual particular: a denominada história pátria, cujo origem pode ser explorado na Colômbia a partir de 1850 com o Compêndio da história de Nova Granada de José Antonio de Plaza, o Catecismo republicano de Cerbeleón Pinzón e, posteriormente, com os livros escritos por José Joaquín Borda (Historia da Colombia contada às crianças) e José María Quijano Otero (Compêndio de História Pátria). Queremos destacar que a História pátria não é exatamente o mesmo que a história nacional, que seu caráter de compêndio ou resumo define não apenas umas práticas especificas da escritura histórica, mas que ademais segue unida aos gêneros literários estabelecidos pela retórica e que seu caráter de "oralidade" define as potencialidades dos livros e dos seus conteúdos, mais em relação com a memória do que com os limites de um saber objetivo e reflexivo.

Palavras chave: Colombia, história, nação, memória, oralidade. 


\section{A modo de introducción. La historia patria}

La escritura de la historia de Colombia discurre en forma paralela al nacimiento de la República. En 1827, José Manuel Restrepo (1781-1883) publica en París la Historia de la República de Colombia ${ }^{2}$, a la sazón un libro prácticamente contemporáneo de los sucesos que dieron lugar a la guerra de la Independencia y a la fundación de la República, conocida por la historiografía como la Gran Colombia. El libro de Restrepo gozó de gran prestigio entre los grupos letrados, convirtiéndose en punto de partida del relato histórico en el país y en los Estados vecinos, dado que abarcaba los hechos acaecidos en Ecuador y Venezuela, partes integrantes de Colombia en aquel entonces. Desde su publicación, el escrito de Restrepo se consideró fuente incuestionable de los datos acerca de los acontecimientos épicos de la Independencia y del origen de la República.

Dos décadas después, el general Joaquín Acosta (1799-1852), militar veterano, científico y filántropo, escribió el Compendio del descubrimiento y la colonización de la Nueva Granada en el siglo $X V P^{3}$, libro con descripciones etnográficas y paisajísticas del país que afianzaban el relato de los hechos descritos acerca de la conquista y el poblamiento del territorio neogranadino. Por su parte, el abogado José Antonio de Plaza (1809-1854) publicó en 1850 dos textos que daban una visión panorámica del pasado de Colombia desde antes del descubrimiento hasta su formación republicana: Memorias de la Historia de la Nueva Granada y el Compendio de la Historia de la Nueva Granada. La singularidad de José Antonio de Plaza estriba en que no solo pensó un texto monumental de historia, sino que suplió la necesidad de un libro de historia más sencillo y menos extenso, y por lo tanto de más fácil comprensión para un amplio público. Por eso, a la par de sus Memorias, escribió un resumen o compendio, cuyo propósito era llenar el vacío de obras históricas destinadas a la escuela y en general a todos aquellos que quisieran conocer el pasado ${ }^{5}$.

La preocupación de J. A. de Plaza por la ausencia de libros apropiados para dar a conocer el pasado patrio no fue una extrañeza. Este escritor catalizó el interés por el estudio de la historia patria de los pobladores de la entonces Nueva Granada, por medio de textos adecuados para ese propósito. En aquel entonces el país carecía de publicaciones y cátedras idóneas para los menos ilustrados, razón por la cual se

\footnotetext{
${ }^{2}$ Restrepo, José Manuel. Historia de la Revolución de Colombia en la América Meridional (París: Librería Americana, 1827).

${ }^{3}$ Acosta, Joaquín. Compendio del descubrimiento y colonización de la Nueva Granada en el siglo decimosexto (París: Imprenta de Beau, 1878).

${ }^{4}$ Biblioteca Nacional de Colombia (BNC), Fondo Arciniegas 10576. Plaza, José Antonio de, Memorias para la Historia de la Nueva Granada desde su descubrimiento hasta el 20 de julio de 1810 (Bogotá: Imprenta del Neogranadino, por Ramón González, 1850).

${ }^{5}$ Biblioteca Nacional de Colombia (BNC) Fondo Pineda 748, pieza 6. Plaza, José Antonio de, Compendio de la historia de la Nueva Granada, desde antes del descubrimiento, hasta el 17 de noviembre de 1831. Para el uso de los Colejios nacionales $i$ particulares de la República, i adoptado como testo de enseñanza por la Dirección jeneral de instrucción pública (Bogotá: Imprenta del Neogranadino, por León Echeverría, 1850).
} 
impuso la tarea de componer un texto didáctico para darle a conocer a un público mayoritario el pasado que dio origen al país.

Emiro Kastos (1825-1884), uno de los periodistas y escritores colombianos más consagrados de la segunda mitad del siglo XIX, escribió, a propósito de las Memorias de Plaza, un artículo en el periódico El Neogranadino en el que, grosso modo, lamentaba el desinterés por los estudios históricos los cuales eran "[...] mirados con desdén e indiferencia" 6 , al tiempo que destacaba su valor "[...] para todo hombre de letras, bien sea filósofo, publicista o poeta"?.

No es una paradoja. La temprana aparición de libros históricos referidos al pasado de la entonces Nueva Granada -libros seminales para la configuración de una narrativa común sobre el origen de la república- no coincidía con lo que Kastos identificaba como desdén y preocupación por el conocimiento del pasado, el cual no solo debía interesar a los hombres de letras sino a cualquier individuo que tuviera la pretensión de "[...] sentar plaza de medianamente civilizado" . En otras palabras, los estudios históricos debían ser de interés general, ya que con ello se despejaba el camino a la civilización, el mismo que debía seguir la sociedad en su conjunto; sin embargo, todavía este era un conocimiento marginal, refundido en la geografía y en la cronología, a pesar de que se contara con obras históricas que, como la de Restrepo, eran un hito del pasado patrio y una fuente de consulta imprescindible; con todo, este era un libro de acceso restringido para la mayoría de la población, para la cual los libros eran o bien artículos de lujo, o no estaba lo suficientemente familiarizada con la lectura individual, siendo la oralidad y la lectura mediada por sus principales fuentes de acceso al pasado histórico.

Así las cosas, la enseñanza del pasado era una deuda de la sociedad consigo misma, indispensable para fortificar los sentimientos de admiración y respeto por la generación que con su lucha y triunfo había dado origen a una nueva república, independiente de España y responsable en adelante de su propio destino. Por tanto, se asumía que el pasado patrio ayudaría a infundir en los ciudadanos sentimientos patrióticos que garantizaran la vida y el porvenir de la entonces Nueva Granada.

La existencia de una escritura histórica reconocida no implicaba, necesariamente, que esta gozara de popularidad entre el grueso de la población. Tampoco indicaba que se hubiera aclimatado un ambiente formal y propicio para hacer de la enseñanza de la historia un aliado en la formación cívica y política, una escuela de la experiencia y un rito memorioso destinado a movilizar el orgullo y el fervor patrióticos: la historia patria, como ámbito del saber, aún no existía de una manera nítida. La tarea de difundir los hechos del pasado que habían dado origen al país corría por cuenta de un

${ }^{6}$ Kastos, Emiro. "Memorias para la historia de la Nueva Granada”, en El Neogranadino, año IV, núm. 144, (Bogotá: 21 de febrero de 1851), p. 62. Cabe anotar que el significado de la palabra publicista remite en el siglo XIX a dos aspectos específicos: el dominio del derecho público y la escritura de textos para darlos a conocer al público.

7 Ibid.

${ }^{8}$ Ibíd. 
espectro de prácticas y manifestaciones colectivas -como el teatro, las festividades públicas, los actos solemnes y su pléyade de cánticos y poetas, los monumentos y la constitución de espacios claves en la recordación- en torno a los cuales se congregaba la sociedad republicana.

Ahora bien, es importante señalar que la historia patria no es una deriva natural ni una consecuencia necesaria del estudio del pasado, ni es una desviación de la escritura histórica del siglo XIX; tampoco es, en su estructura, lo mismo que la historia erudita o académica ni puede confundirse con el saber documentado de un tipo de historiografía erudita originada en la República, como la de Restrepo o Acosta.

La historia patria fue una manifestación específica de un saber histórico entroncado con los procesos de formación política del estado moderno. En este orden de ideas, fue una expresión intelectual de una nueva forma de organización política que requería concitar la voluntad de los ciudadanos en torno a nuevas expresiones políticas y a una realidad que ya no dependía de la monarquía o de la divinidad. La historia patria se constituyó entonces en un saber que significaba una conciencia de patria, en el sentido de una tierra libre y soberana, distinta de otras, y por la cual había que luchar, no solo desde el punto de vista militar, sino asumiendo los deberes que su existencia demandaba de sus habitantes. Constituye un relato verdadero del pasado, patente en la exposición de los deberes de los ciudadanos -los patriotas-, con el compromiso de darlo todo por la patria, sin esperar de ella más que su perennidad libre de todo yugo, soberana y gloriosa9.

Se trata entonces de una expresión concreta del saber histórico decimonónico que aún continúa vigente en la medida en que se mantienen ciertos relatos y personajes sobre los cuales se funda la República, los valores cívicos y muchos de los discursos políticos y gubernamentales. Así pues, la historia patria se desarrolló al unísono de las formaciones republicanas modernas como una especie de punto intermedio entre las antiguas valoraciones de la historia magistra vitae (comprendida por la retórica como un género literario cuya utilidad residía en ser depósito de ejemplos para el porvenir) y los requerimientos de verdad gestados a partir del proceso de formación de la historia en la modernidad, con sus corolarios de racional, progresista y democrático.

A partir de tales consideraciones, este artículo se ocupa de las relaciones entre historia, historia patria y retórica, así como del trasfondo oral que caracterizó a la segunda como un saber propedéutico y emotivo que aunque adquiriese el formato de libro, recurrió a estrategias de verbalización que quedaron plasmadas en la organización de los textos; finalmente, se intenta esbozar la figura del escritor de historia como un sujeto con fuertes lazos sociales y políticos y con atribuciones morales que, en el siglo XIX, legitimaron su papel de vocero de las glorias de los fundadores de la patria.

\footnotetext{
${ }^{9}$ Sobre historia y patria: Annino, Antonio y Rojas, Rafael. La Independencia: Los libros de la patria (México, Fondo de Cultura Económica, 2009); López Lopera, Liliana. "Figuraciones de la tierra natal: patria nación y república”, en Co-herencia, vol. XI, núm. 21 (Medellín:Universidad Eafit, 2014), pp. 97140 .
} 


\section{Retórica, memoria y verdad}

Durante la antigüedad y hasta bien entrado el siglo XIX, la retórica era un saber dominante y transversal a todos los demás. Comprendía un cuerpo de preceptos cuyo propósito era la perfecta disposición del lenguaje -oral y escrito- para un fin determinado, fuera este persuasivo, disuasivo o de convencimiento del auditorio. Dentro de la gran variedad de clasificaciones y prescripciones orientadas a la definición de los tipos de discursos, de sus propósitos, del público, como al lugar de enunciación, la retórica consideraba las distintas tipologías o formas de presentación (elocución) de dichos discursos. Así, en el campo de las llamadas narraciones históricas se incluían las fingidas y las verdaderas. La historia como género no solo no evitaba elementos literarios sino que incluso los estimulaba, justamente porque la pretensión de la historiografía clásica era deleitar y entretener a los lectores u oyentes al tiempo que enseñaba modelos de virtud (y su contraparte, el vicio). A finales del siglo XVIII y, especialmente en el XIX, la pretensión de deleitar cede y el género histórico adquiere un sentido propedéutico, al primar la instrucción (docere) sobre el deleite (deletare) ${ }^{10}$.

La historia verdadera se entendía como “[...] narración de sucesos pasados hecha para instrucción de los hombres presentes y venideros"11, allí residía su utilidad, pues antes que un saber para el deleite o un simple pasatiempo, la historia se desplegaba como una propedéutica de principios morales previamente definidos y asentados en la tradición. De estilo grave y serio, sin chistes ni chocarrerías ${ }^{12}$, coincidía con el papel que se esperaba cumpliera el historiador, un sabio que "[...] habla con la posteridad y nunca ha de hacer el papel de gracioso o bufón"13. El pasado estaba investido de una autoridad seria y sagrada cuya función moralizante permitía, además de la sana conducta, la preservación de la verdad como resultado, no tanto de la indagación, como de la apreciación cuidadosa de los sucesos efectivamente acontecidos. Aunque el historiador debía hacer gala de instrucción, poseer conocimientos geográficos y políticos de todo tipo, auscultar y conocer el género humano, y hacer un grande acopio de materiales ${ }^{14}$, su ocupación era la de pintar fielmente los hechos a través de un relato exacto de los sucesos, destacando en ellos su carácter moral e instructivo, y no la de encontrar datos novedosos o buscar nuevas interpretaciones.

La tarea del historiador era, antes que la de investigador, la de un copista que seleccionaba de un mar de sucesos aquellos cuyos contenidos morales pudieran instruir a la sociedad presente y futura, y la de un narrador metódico que, ceñido a un plan, es decir, a una forma rigurosa de encadenamiento, ligara las causas y las consecuencias en procura de hacer visibles aspectos como el paso de la barbarie a la

\footnotetext{
${ }^{10}$ Hartog, Françoise. "La inquietante extrañeza de la historia”, en Historia y grafia, año XIX, núm. 37, (México: Universidad Iberoamericana, 2011), pp. 181-201.

${ }^{11}$ Gómez Hermosilla, Josef. Arte de hablar en prosa y verso (Madrid: Imprenta Real, 1826), p. 57. Este fue uno de los textos de retórica más conocidos en el país en el siglo XIX, base de los que escribieran Enrique Álvarez Bonilla y José Manuel Marroquín.

${ }^{12}$ Ibid., p. 72.

${ }^{13}$ Ibid.

${ }^{14}$ Ibid., p. 59.
} 
civilización, el transcurso heroico del cristianismo, y, en general, el avance del mundo occidental. Ello presentado desde una perspectiva moralizante en la que la tensión entre la virtud y el vicio se resolvía siempre a favor del primero, justamente porque el objeto de la historia no era servir de pasatiempo, ${ }^{15}$ sino hacer " $[. .$.$] que el pasado nos$ instruya para lo venidero"16.

El pasado estaba allí como una totalidad de la que el historiador extraía con fidelidad los sucesos importantes para la moralización presente y futura, y fue este el modelo que imperó en la sociedad hasta bien entrado el siglo XIX, pues la retórica hacía parte de los planes de estudio y era un saber cuya larga trayectoria en la cultura occidental había hecho de él un sustrato común, presente de muchas maneras y a través de diversas prácticas.

La enseñanza de la retórica -y con ella la de las narraciones históricas verdaderasestaba fuertemente signada por la oralidad, justamente porque la primera fuente de la enseñanza retórica estuvo dirigida al orador y a la forma oral del discurso. La oralidad prevaleció como una forma dominante en la transmisión y circulación de los aspectos fundamentales de la vida comunitaria; ella fue una vía central en el adoctrinamiento religioso, y crucial (lo sigue siendo) en los procesos educativos, cuya principal mediación corría por cuenta de la palabra que se grababa en la memoria para ser recitada, o para ser copiada y glosada con posterioridad por los comentaristas. La oralidad era una vía legítima, incluso privilegiada, en la transmisión del saber; la retórica tocó este asunto con particular cuidado: la dicción era un arte total, pues a la vez que permitía la exhibición de la inteligencia del orador, regía su capacidad para expresarlo con exactitud, corrección y belleza, con el propósito de movilizar, mediante el cuidado de la palabra, los sentimientos del auditorio.

La retórica contemplaba fórmulas para la composición de historias verdaderas, y también estipulaba preceptos tendientes a la comprensión de los textos por parte del auditorio. La inteligibilidad constituía un problema central a la hora de enunciar un discurso (fuese éste oral o escrito) y tanto el auditorio, el espacio de enunciación, como la elocución, estaban fuertemente regladas, de modo que la comprensión permitiera el lucimiento del orador, al tiempo que repercutía directamente en el intelecto y en el sentimiento de aquellos a quienes se dirigía. Aparte de la preceptiva sobre la producción del discurso, la retórica consideraba también el estilo del mismo dependiendo de la calidad del público y del propósito del texto; a la vez implantaba normas morales para refrendar o no la autoridad de quien lo componía, autoridad que casi siempre estaba relacionada más con su posición social y su condición moral, que con aspectos netamente cognitivos.

En este marco preceptivo se definió el estilo didáctico, cuyo objeto era, principalmente, enseñar aspectos sustantivos de forma simple y clara a públicos poco versados en una temática específica, sin que por esta razón los discursos cayeran en la vulgaridad o en

\footnotetext{
${ }^{15}$ Ibid., p. 69.

${ }^{16}$ Ibid.
} 
la falta de elegancia en el lenguaje, y dispuestos además a quedar grabados, mediante la repetición, en la memoria de los aprendices. La memoria era una facultad que se debía ejercitar "como auxiliar poderoso en el desarrollo de las demás" ${ }^{17}$, para lo cual Martín Lleras (1841-1887) -influyente educador del medio siglo colombianorecomendaba hacer aprender a los alumnos algunas fábulas “[...] en parte del tiempo destinado a la lectura; i al escojerlas se procurará que sean cortas [...]" para que las "[...] aprenda a fuerza de repetición"18.

Los aspectos señalados hasta aquí permiten entender que en un contexto signado por la retórica, la dicción de discursos seguía siendo uno de los elementos más relevantes para inculcar y promover el aprendizaje de los saberes, lo cual puede sumarse al hecho de que durante el siglo XIX los libros aún seguían siendo un artículo de lujo para el promedio de los colombianos, y los impresos populares, aunque circularan, eran objetos de cuyos favores no gozaba toda la sociedad de forma directa. Dichas consideraciones permiten entender el saber histórico conocido en el país en el siglo XIX, un saber en el que todavía quedaban remanentes de las formas orales de transmisión, así como de la preceptiva que estipulaba las normas para la configuración de discursos comprensibles según las condiciones culturales del auditorio. $\mathrm{Y}$ es precisamente por eso por lo que la retórica resultaba un camino de gran utilidad a la hora de hacer los desbroces entre los tipos de textos históricos y los públicos posibles a los que iban dirigidos, así como de la manera de asumir los saberes en relación con los propósitos que se pretendían.

Por eso afirma que pueden identificarse modos de pensar y de hacer uso del saber histórico en el país, cada uno con finalidades distintas: por un lado, libros hechos para públicos diestros en la lectura y comprensión de textos extensos, mucho más elaborados para el estudio y la reflexión, y otros pensados para un público amplio, cuya forma didáctica se acompasaba con la sencillez y legibilidad requeridos para la enseñanza e inculcación de verdades dirigidas a movilizar pasiones más que a la reflexión sistemática de sus contenidos. Las palabras de Emiro Kastos señaladas con antelación reflejaban esta situación, pues, a pesar de que ya hacia 1850 se contaba con libros que sintetizaban algo más de los trescientos años de la historia de Colombia, aún no se había adelantado mayor cosa en lo que se refiere a la enseñanza y la difusión del pasado del país. Y no es que este aspecto estuviera del todo descuidado, la historia se enseñaba en diversas asignaturas: cronología, geografía patria, historia sagrada y profana y hasta las representaciones teatrales de eventos de la Independencia comprendían un vasto y complejo ámbito de conocimiento del pasado colombiano, un pasado con el que se buscaba despertar amor, pasión y orgullo por la emergente república que reclamaba su derecho a la soberanía, la autonomía y la defensa de su libertad.

\footnotetext{
${ }^{17}$ Lleras, Martín, "Pedagogía”, en Escuela Normal, Periódico Oficial de Instrucción Pública, t. III, núm. 96 (Bogotá: Estados Unidos de Colombia, 26 de octubre de 1872), p. 343.

${ }^{18}$ Ibid.
} 


\section{Historia patria, libros y oralidad}

Tal ausencia, puede decirse, respondía a la falta de existencia de un saber organizado y definido como historia de Colombia, precisamente porque ese saber figuraba en la medida en la que el país alcanzaba una existencia republicana distinta de la española, valga decir, que la importancia que se empezó a dar a la enseñanza de la historia patria coincidió con la formación de una conciencia histórica específicamente preocupada por el pasado del terruño, un pasado considerado propio, distinto y separado del de España. La historia patria es el resultado de la conciencia histórica colectiva que se entiende como única, distinta y en pie de defensa permanente contra los agresores (externos) que pueden mancillar su pasado y poner en riesgo su porvenir. Y cuando la preocupación emergió hacia 1850, respondía a un ambiente propicio para el estudio del pasado patrio, precisamente porque ya se había desarrollado esa conciencia y con ella la de la necesidad de incentivar el afecto, la lealtad y el orgullo por el naciente país del que se era oriundo y porque era clara la diferencia entre este y España, amén de los vecinos con los que había compartido los primeros años de su vida republicana.

Ningún discurso, ningún saber se produce al margen de su enunciación, sea esta oral o escrita. El acto de enunciación configura un universo de relaciones históricas y culturales que aseguran la organización del pensamiento en la dicción o en la escritura y en la decodificación lingüística, también en los modos de apropiación. Sean adoptados, adaptados o radicalmente modificados, los discursos solo adquieren sentido en relación con la época y las tradiciones culturales de los públicos que los apropian ${ }^{19}$. Pensar la historia patria como un saber con dos formas relacionadas de concreción (escritura y oralidad) permite entender, además de las condiciones epistemológicas en las que se pudo haber formulado, los soportes y las condiciones performativas ${ }^{20}$ que facilitaron el acceso del público a sus contenidos $\mathrm{y}$, eventualmente, prever los sentidos y los usos por parte de una comunidad, no siempre habilitada en la decodificación, pero sí habituada a modos de comprensión, memorización y lectura realizados a partir del intercambio oral. De igual forma, ayuda a dar un paso más en procura de comprender algunos mecanismos sociales de reconocimiento institucionalizado, de apreciación y de correspondencia cultural que invistieron a unos cuantos personajes de la autoridad especial de escribir las versiones del pasado para la mayoría, versiones que fueron presentadas según los formatos, las manifestaciones narrativas y mecanismos de oralización comunes y fácilmente identificables por la sociedad, porque además, ellos mismos encarnaban atribuciones acerca de la verdad, el saber y los modos de aprender culturalmente establecidos ${ }^{21}$.

\footnotetext{
${ }^{19}$ Ricœur, Paul. Tiempo y narración III, El tiempo narrado (México: Siglo XXI, 1996). Interesa la refiguración como capacidad de transformación de la experiencia por la acción del relato gracias a que existen condiciones de inteligibilidad: tradiciones narrativas, de formato y de organización que permiten que una comunidad se apropie de diversas narraciones.

${ }^{20}$ MacKenzie, Donald Francis. Bibliografía y Sociología de los textos (Madrid: Akal, 2005). Un texto comprende los soportes y su performatividad, aspectos ineludibles para entender su historia, su uso y los modos de apropiación por parte de las comunidades de lectores u oyentes.

${ }^{21}$ Bourdieu, Pierre. ¿Qué significa hablar? (Madrid: Akal, 2001). En este texto, además del carácter performativo del lenguaje, Bourdieu explora su valor simbólico como signo de riqueza y distinción.
} 
La oralidad estaba presente de manera rotunda en todo el sistema de enseñanza, y mucho más cuando se trataba de la inculcación de conocimientos y preceptos que buscaban alcanzar un público mayor al que entonces podía asistir a las aulas. Entender la historia en su forma patria es entender los contenidos simplificados y presentados de manera dialógica a través de preguntas y respuestas como en los catecismos, o en párrafos numerados acompañados de cuestionarios que ayudaban a memorizarlos y luego recitarlos con exactitud. Es pensar que para una mayoría poco familiarizada con la lectura y con la posesión de libros, la oralización y la memoria eran métodos eficaces para el aprendizaje de los sucesos, principios y preceptos fundamentales que habría de conocer todo ciudadano colombiano de la época.

El estudio de la historia patria requiere entonces, no solo del análisis exegético de los contenidos, sino de la auscultación de marcas de oralidad que quedaron vertidas en los libros; es, en suma, un saber que se constituye a partir de la relación entre escritura y oralidad, entre memoria y recitación, entre conocimiento del pasado y pasión por los hechos que hicieron posible la libertad y la existencia de la patria. Un saber específico que da noticia de la enseñanza, la divulgación de los contenidos validados, del estatuto mismo de la historia en el siglo XIX y de su transición entre un saber memorioso y narrativo a un saber objetivo representado por la escritura.

A veces se ignora que gran parte del conocimiento se registró y circuló tanto diacrónica como sincrónicamente a través de técnicas que conjugaban la memoria y la palabra, como el catecismo, la rima y la poesía ${ }^{22}$, y que fue a través de la viva voz como se pudo poner al alcance de vastos públicos habituados y no habituados a la lectura. Los sermones, por ejemplo, fueron verdaderas vías de transmisión de ideales, normas y noticias entre grandes grupos poblacionales y su poder aleccionador no disminuyó con los impresos, sino que, incluso, los sermones publicados se vendían con relativa frecuencia ${ }^{23}$. Parte de la vida política circulaba a través de textos impresos populares que muy seguramente se leían en espacios públicos, fijados en los muros de las ciudades y de las casas, oralizados por mediadores de la lectura y comentados por todos: juicios de prensa, hojas sueltas de diversa índole, polémicas, panfletos, una infinita variedad de textos impresos y manuscritos que ponían al alcance de todos noticias, consejas, cotilleos, etcétera.

\footnotetext{
${ }^{22}$ Hay textos ya clásicos que han estudiado las alternancias entre oralidad y escritura, entre memoria y registro, y que asumen a la escritura como una tecnología y a la memoria como una técnica que permitió (y permite) almacenar y actualizar colectivamente información crucial para la cultura. Havelock, Eric. Prefacio a Platón (Madrid: Visor, 1994); Ong, Walter. Oralidad y escritura, tecnologías de la palabra (México: Fondo de Cultura Económica, 2009); Goody, Jack (comp.). Cultura escrita en sociedades tradicionales (Barcelona: Gedisa, 2003).

${ }^{23}$ Silva, Renán. "El sermón como forma de comunicación y como estrategia de movilización en el Nuevo Reino de Granada a principios del siglo XVIII”, en Revista Sociedad y Economía, núm. 1, Cali, Universidad del Valle, 2001, pp. 103-130. El sermón sirvió para adherir a los ciudadanos a los ideales republicanos: Biblioteca Nacional de Colombia (BNC), Fondo Pineda 182, pieza 1. Fernández de Sotomayor, Juan. Sermón que en la solemne festividad del 20 de julio, aniversario de la libertad de Nueva Granada predicó en la Santa Iglesia Metropolitana de Santafé (Santafé: Imprenta de C. B. Espinosa por el C. Nicomedes Lora, año de $1815,3^{\circ}$ ).
} 
Parte de las habilidades de los hombres públicos se desarrollaban a través del estudio de la retórica (que comprendía la organización y la secuencia como procesos del pensamiento, así como su correcta y eficaz enunciación) y se expresaban en su capacidad oratoria, en la destreza para dirigirse en voz alta a un público que debía conservar el interés durante largas jornadas de exhibición del poder oratorio del tribuno y persuadir, mediante estudiados argumentos a un público no siempre dúctil y al que, aparte del cuidado retórico, importaban las calidades morales del orador ${ }^{24}$. De allí que fuese precisamente la de la oratoria una de las habilidades que más se apreciaban y un imperativo entre los hombres públicos, cuya autoridad moral, intelectual y política se encarnaba en su capacidad para entonar largos y apasionados discursos en diversos cuerpos colegiados y en la plaza pública.

En los exámenes anuales presentados por los estudiantes de los distintos colegios del país, la palabra dicha era una parte crucial en la demostración de las destrezas de los estudiantes, por eso se procuraba "[...] sin prejuicio de la exposición de todas las materias que se han cursado en la escuela" ${ }^{25}$ disponer de estrategias como las boletas con preguntas que sacaban a la suerte: "[...] los alumnos contestaban a su contenido, obteniéndose de este modo, con ventaja, hacer discurrir a los alumnos por sí mismos, i acostumbrarlos a deliberar en público"26.

Se dice que la actividad política en el siglo XIX y en pleno surgimiento de la república no se entiende sin tener en cuenta la oratoria, su capacidad de convocatoria y las calidades intelectuales, morales y políticas que generalmente se asociaban al buen orador, además el resurgimiento de la oratoria coincidió con la organización de la república, dado que los órganos colegiados y la actividad de sus miembros estaba claramente establecida por la exposición pública de ideas, por la defensa a viva voz de las posturas y por la presentación pública de los proyectos, amén de las polémicas partidistas. La vida política estaba claramente entroncada con la habilidad oratoria de los representantes, quienes debían exhibir sus virtudes patrióticas a partir del uso cuidadoso de la palabra entre sus congéneres: convencer y persuadir antes que imponer o hacer uso de la violencia física.

Como colofón es indispensable agregar un aspecto que a veces es poco enfatizado: la retórica es uno de los rasgos más notables en cuanto a la contención de la violencia, ya que la palabra convertida en instrumento político consiguió imponer (en muchas ocasiones) el poder del lenguaje sobre la fuerza bruta.

\footnotetext{
${ }^{24}$ Murilo Carvalho, José. "Historia intelectual: la retórica como clave de lectura", en Prismas: revista de historia intelectual, núm. 2 (Argentina: Universidad Nacional de Quilmes, 1998), pp. 149-168.

${ }^{25}$ García, Abraham. "Exámenes presentados por los alumnos de la Escuela Normal de Medellín”, en $L a$ Escuela Normal, periódico oficial de Instrucción Pública, t. III, núm. 101 (Bogotá: Universidad Nacional, 7 de diciembre de 1872), p. 385.

26 Ibid.
} 


\section{Libros de historia patria, una tradición compendiada}

En 1850, durante el gobierno de José Hilario López (1798-1869), se expidió un decreto que organizaba los colegios nacionales y que legislaba acerca de la enseñanza de la historia y estadística de la Nueva Granada ${ }^{27}$ en los colegios de literatura y filosofía, mientras que en los de ciencias naturales, física y matemática se disponía la enseñanza de la geografía particular de la Nueva Granada ${ }^{28}$. Dicha legislación informa no solo de la creciente importancia del pasado, sino de la conciencia histórica y territorial que entonces se forjaba. De modo que empezó a definirse un campo con catedráticos especializados que debían "[...] proponer la traducción e impresión de obras adecuadas al efecto" 29 , es decir, letrados, que a la vez debían impartir lecciones orales y una vez a la semana hacer en ellas "[...] aplicaciones de las doctrinas i los principios que enseñan, a las necesidades, intereses i peculiares circunstancias del país" ${ }^{30}$. La enseñanza de la historia en los colegios nacionales combinaba el uso de textos escritos y lecciones orales por parte del profesor, así como los exámenes y las pruebas verbales en las que los estudiantes mostraban el grado de aplicación y conocimiento adquirido en las clases y sus habilidades oratorias para dirigirse a otros.

Se dice que la historia patria no es un discurso en abstracto, ni una desviación del saber histórico; es una manera particular de narrar el pasado del país concordante con el ideal de convertir a cada ciudadano en defensor de los valores y principios políticos que sustentan la república. En este sentido, la historia patria no es sinónimo de una historia nacional, toda vez que la última remite a un campo de mayor reflexión crítica en la que los textos suponen, antes que el despliegue de la memoria y la recitación de los contenidos, una visión crítica, relativamente depurada, de los hechos, que si bien buscan narrar procesos históricos, también tienen la función formativa en términos de reconocimiento y respeto de las diferencias culturales y políticas, mientras que la historia patria se presenta como un saber convenido y estereotipado, en el que poco lugar tienen las posiciones contrarias, las voces disidentes o las culturas en disputa. Este es un punto fundamental en el siglo XIX colombiano en el que las tensiones políticas e ideológicas mantenían en vilo la institucionalidad; por ello, los contenidos en términos de historia patria remitían a una serie de acontecimientos y personajes presentados de manera que no generaran divisiones, sino que fueran un punto de encuentro e identificación cívica y moral de los ciudadanos.

Por eso, para entender la especificidad de dicho saber, es necesario entroncarlo con las tradiciones; pero también analizarlo en el contexto de la cultura libresca dentro de la cual cobró forma y se desarrolló. La historia patria tiene sobre todo una forma: la del libro de historia patria, menos voluminoso y de pequeño tamaño, en cuyas páginas desfilan héroes y antihéroes, acontecimientos apoteósicos que dieron origen a

\footnotetext{
27 "Decreto que organiza los colegios nacionales de la república", en Gaceta Oficial, año XIX, núm. 150, Bogotá, 1850, p. 441.

${ }^{28}$ Ibid.

${ }^{29}$ Ibid., p. 443.

${ }^{30}$ Ibid.
} 
la Independencia, con fechas y arengas, con modelos de virtud cívica y arrojo político; $\mathrm{y}$, en el caso del siglo XIX, con ausencia total de ilustraciones, lo cual se compensaba con el uso de vívidas descripciones y figuras retóricas como el retrato, la semblanza y la cohortatio, cuya función era presentar hechos y personajes en forma memorable y a la vez justificar las acciones de los héroes, a través de la rememoración de los agravios, las ofensas y los daños ocasionados por el enemigo español ${ }^{31}$.

La historia patria se encarnó en el libro, por una parte, de las tradiciones retóricas que facilitaban, desde la forma didáctica, la inculcación de saberes que en el siglo XIX seguían encarnando preceptos morales, y por otra, de la existencia de una forma singular de organizar el relato del pasado que contaba con antecedentes narrativos del mismo; versiones acordadas y relativamente canonizadas, toda vez que dichos libros no buscaban establecer nuevos derroteros en la comprensión de los sucesos pretéritos, sino resumir, compendiar y simplificar versiones comunes y comprensibles para todos, y se dice para todos en el sentido en que ellos servían de guía cívica y política, tanto a letrados como a no letrados.

No resulta fortuito que el abogado José Antonio de Plaza escribiera su Compendio dos años después de que lo hiciera con sus Memorias, como consta en el privilegio de publicación concedido a las Memorias en 1848 (aunque fuese publicado en 1850). ${ }^{32}$ En el Compendio, Plaza organizó “[ [...] una narración metódica y suscinta de los hechos más notables, en acápites numerados" ${ }^{33}$, mientras que en las Memorias resaltaba la dificultosa labor de "[...] leer muchos fárragos i ojear una infinidad de documentos" y extraer de esas lecturas lo que "aparecía acorde i conforme con la verdad de los hechos". ${ }^{34}$ Esos textos, de uso popular, resultaban de horas de trabajo en procura de seleccionar los datos, los personajes y los acontecimientos convertidos en referentes del pasado e hitos fundadores de la patria, una narración de hechos políticos y militares basada en versiones extraídas de autores, periódicos y contrastada con alguna incipiente documentación que servía para relatar de la manera más fidedigna y neutral posible todos los eventos.

Ya se ha dicho que no se trataba de una indagación para hallar un dato inédito o proponer una nueva interpretación; porque estos textos estaban motivados por el afán de divulgar las versiones que permitieran un relato, unos héroes y unos referentes comunes del pasado sobre el cual se fundaba el nuevo orden. El esfuerzo se hacía en la organización, la numeración y la construcción de preguntas que ayudaran a fijar en la memoria los contenidos para que a la hora de ser recitados el paso de la mente

\footnotetext{
${ }^{31}$ Navarro Antonín, Fernando. "La retórica del discurso: La cohortatio: tradición clásica y pervivencia", en Cuadernos de filología clásica y estudios latinos, núm. 19, Madrid, Universidad Complutense, 2000, pp. 79-124.

${ }^{32}$ Biblioteca Nacional de Colombia (BNC), Fondo Arciniegas 10756. Plaza, José Antonio de, Memorias, "Privilegio de publicación".

${ }^{33}$ Biblioteca Nacional de Colombia (BNC), Fondo Pineda 748, pieza 6. Plaza, José Antonio de, Compendio de historia, "Introducción".

${ }^{34}$ Ibid.
} 
a la palabra se hiciera más fácil y ordenadamente, y como bien lo afirmaba José Joaquín Borda en su Historia de Colombia contada a los niños, publicada en 1870, dar a la narración “[...] un carácter ligero, descargándola de fechas y nombres poco importantes" 35 .

En el mismo sentido se refería José María Quijano (1836-1783), una figura destacada en su época por su inclinación a los estudios históricos, y por su afición a publicar temáticas alusivas al pasado patrio. En el prólogo de su Compendio de la historia patria, publicado en 1874, decía: "Poco hallarán de nuevo los lectores en este compendio" 36 pues, por su misma naturaleza no podían "[...] intercalarse documentos recientemente hallados, dar cuenta de acontecimientos ocurridos en la época colonial de que no se habían tenido conocimiento, o maravillosos episodios de la guerra magna que mis predecesores han omitido" 37 .

La escritura de un libro de historia patria era una labor que se hacía después de haber alcanzado renombre en el campo de las letras, los estudios históricos y la vida social; no era pues una incursión aleatoria o un capricho de escritor. Ocuparse del estudiar, seleccionar y escribir sobre el pasado patrio era una manifestación inherente al nivel social, cultural y político de quien asumía esta misión, momento reservado a muy pocos. Ya se menciónó a José Antonio de Plaza, escritor de unas Memorias y un Compendio y personalidad política cercana a grandes figuras de la época como el General Santander. Su faceta de escritor se vio reflejada en la producción de textos de uso popular como un almanaque y un libro de estadística, este último resultado de los cursos de estadística que regentó en el Colegio Nacional de Bogotá, escribió un romance y varias polémicas y ocupó diversos cargos públicos ${ }^{38}$.

José Joaquín Borda (1835-1878) fue uno de los literatos más reconocidos de la mitad del siglo XIX, además de la Historia de Colombia contada a los niños (1870), publicó también en 1872 la segunda parte dedicada a la vida republicana con el nombre de La República en Colombia; ambas piezas se unieron en un libro llamado Compendio de Historia de Colombia del que se pueden rastrear varias ediciones hasta $1929^{39}$, al tiempo compuso una Historia de los Jesuitas en la Nueva Granada, editada en París, que se ofreció en las páginas del periódico El Mosaico:

\footnotetext{
${ }_{35}^{35}$ BNC, Miscelánea 60. Borda, José Joaquín. Historia de Colombia contada a los niños (Bogotá: Imprenta de El Mosaico, 1872), "Prefacio".

${ }^{36}$ Biblioteca Nacional de Colombia (BNC), Fondo Pineda 789. Quijano Otero, José María. Compendio de historia patria para uso de las escuelas primarias (Bogotá: Imprenta de Medardo Rivas, 1874, 1ª edición en libro).

${ }^{37}$ Ibid.

${ }^{38}$ Ibáñez, Pedro M. "José Antonio de Plaza”, en Papel Periódico Ilustrado, año V, núm. 109 (Bogotá: Imprenta de Silvestre y compañía, 1887), pp. 197-200.

${ }^{39}$ Borda, José Joaquín. Compendio de Historia de Colombia (Bogotá: Sociedad Editorial, 1929).
} 
“[...] consta de dos volúmenes lujosamente impresos y empastados, con dos finos retratos trabajados en Alemania" 40 .

El libro de José María Quijano Otero publicado en 1874, contó con una edición previa por entregas en el periódico La Escuela Normal, dedicado a la instrucción pública entre 1872 y $1874,{ }^{41}$ escrito en el marco de su trabajo de quince años continuos al frente de la cátedra de Historia patria en la Escuela de Literatura y filosofía en la Universidad Nacional, al tiempo que ejercitaba su pluma como escritor histórico en el periódico La América o en acaloradas polémicas sobre el pasado patrio. Entre 1868 y 1873 dirigió la Biblioteca Nacional, fue secretario de la Cámara y representante por Antioquia. Su colección de documentos antiguos, impresos y manuscritos, reforzó socialmente su reputación de erudito y voz autorizada para contar la historia patria.

La escritura de un libro de historia patria, así como la definición de la especificidad de este saber, solo se comprende en tanto se entienda que ella no era el resultado de la improvisación. Su relativa simpleza no puede ser vista como fruto de la mediocridad o de la falta de rigor metodológico en la composición y la organización de los contenidos. La escritura de la historia patria constituía un ámbito que requería de conocimientos amplios, criterios claros, documentación y gran erudición; condiciones adquiridas después de mucho tiempo de estudio, de la publicación de diversas obras y del reconocimiento público de los escritores, como estudiosos del pasado patrio, con publicaciones previas sobre el tema. Además, debían gozar de buena reputación como hombres de bien, ciudadanos comprometidos con la república, cumplidores de su deber patriótico como defensores y promotores de la virtud cívica.

Valga decir que el estudio y el conocimiento exhaustivo de documentos impresos y manuscritos, así como de libros sobre el pasado patrio, fue una condición inquebrantable; así lo señalaban las directivas de la Universidad Nacional en 1872 al referirse a que el profesor de historia patria "[...] tiene que dedicar gran parte de su tiempo al estudio de las pocas obras que existen sobre la materia i a la consulta de crónicas y manuscritos" ${ }^{\prime 2}$.

\section{Marcas de oralidad}

Si se ha entendido a la historia patria como una manifestación específica del saber histórico en el contexto de la formación de los estados emergentes, es también un

\footnotetext{
40 “Avisos”, en El Mosaico, Periódico dedicado exclusivamente a la literatura, año II, núm. 20 (Bogotá: El Mosaico, 4 de junio de 1872), p. 160. Las descripciones físicas no deben ser pasadas por alto, un libro era una inversión: los suscriptores y compradores reclamaban que las características anunciadas fueran ciertamente cumplidas por la edición. Darnton, Robert. El negocio de la Ilustración. Historia editorial de la Encyclopedie 1775-1800 (México: Fondo de Cultura Económica, 2006).

${ }^{41}$ El Compendio de historia patria, de Quijano Otero fue publicado en el periódico La Escuela Normal entre el t. III, núm. 97 del 9 de noviembre de 1872 y el t. V, núm. 207 del 19 de diciembre de 1874. El gobierno pagó $\$ 600$ por la entrega de diez pliegos impresos del texto.

42 "Decreto por el cual se incrementa el sueldo al catedrático de Historia Patria de la Escuela de literatura y filosofía de la Universidad Nacional", en Anales de la Universidad, t. IV, núm. 37 y 38 (Bogotá: Universidad Nacional, 1872), p. 38.
} 
punto en el que pueden evidenciarse ciertas transiciones entre la historia magistra vitae, de cuño retórico y la historia en su forma moderna, como un conocimiento analítico, signado por procedimientos objetivos, técnicas en el manejo documental y una escritura definida por la interpretación y no por la pretensión de fidelidad del relato. Definir el análisis histórico moderno como una escritura es una manera de mostrar las características orales concomitantes a la denominada historia patria. No se pretende establecer una ruptura radical con la divulgación oral y las mediaciones que enriquecen la circulación de la historia en su forma moderna, sino destacar que esta cobra relevancia en los medios académicos ante todo como escritura con características tipográficas y de presentación que le son inherentes; mientras que en el siglo XIX, la historia patria era una escritura que cobraba relevancia en la medida en que llegaba a los ciudadanos, supieran leer o no. Por eso, los textos comprendían también algunos elementos didácticos que ayudaban a memorizarlos y recitarlos. La memoria no era solo una facultad del aprendizaje; era, sobre todo, una experiencia colectiva que se actualizaba de manera permanente mediante acciones performativas: representaciones, festividades públicas, actos cívicos cuya función era mantener vivo en el recuerdo comunitario los acontecimientos considerados fundamentales para todos.

En tal sentido, más que un discurso objetivo o un conocimiento racional, la memoria estaba vinculada a acciones, momentos y espacios concretos y a una concepción del pasado como verdad incuestionable que debía aprenderse rigurosamente, es decir, sin lugar a dudas ni a cuestionamientos. En la historia patria confluían los requerimientos memoriosos, acciones vinculadas a la reivindicación comunitaria expresadas mediante prácticas concretas, un saber destinado a la memoria y a la rememoración. Igualmente, era un saber construido sobre bases canónicas que servían, en un contexto políticamente convulsionado, como narración que hermanaba sobre la base de hechos, personajes y eventos, a una sociedad dividida por las tensiones partidistas y regionalistas. Esto puede explicar el especial interés por la Independencia, fuente también de tensiones políticas, pero matizadas por ideas como las del prócer o el mártir para mantener “[...] vivo el recuerdo de los ilustres mártires de aquella causa"43, con una finalidad precisa: "[...] recomendar las heroicas acciones de valor i de patriotismo que ilustran la guerra con tanto honor i tanta gloria sostenida en defensa de la misma causa"44.

Los libros mencionados aquí dejaron en sus páginas huellas sobre cómo debía darse a conocer la historia patria: el uso de párrafos cortos y numerados, la organización cronológica del relato, la inclusión de cuestionarios al final de cada capítulo son marcas que denotan una motivación propedéutica y el énfasis en la memorización y moralización de los contenidos. En el Compendio de José Antonio de Plaza se nota la correspondencia entre los párrafos numerados y las preguntas al final de cada lección; la pregunta treinta del final de la lección I “¿Cuáles fueron las cualidades de

\footnotetext{
${ }^{43}$ Biblioteca Nacional de Colombia (BNC), Fondo Pineda 19, pieza 3. Pinzón, Cerbeleón. Catecismo republicano para Instrucción popular, redactado a escitación del ciudadano presidente Manuel Murillo, destinándolo con especialidad a las escuelas de los cuerpos de guardia colombiana, creados por el decreto presidencial de $1^{\circ}$ de setiembre de 1864 (Bogotá: Imprenta de El Mosaico, 1864), p. 4.

${ }^{44}$ Ibid.
} 
Colón?" "45, coincidía con el numeral treinta de la misma lección en el que puede leerse: “30. Fue Colón de jentil estatura, largo de cara, i en sus facciones se descubría el jesto de la autoridad. De bien hablar, claro injenio, grave con moderación, afable con los estraños, i de índole apacible i suave. Sobrio i moderado en las necesidades de la vida $[\ldots]^{\prime 46}$. La relación entre la pregunta y la respuesta creaban una unidad nemotécnica que además de fijar en la memoria, ayudaba a desplegar con exactitud la palabra en el momento de la recitación pública como la que se hacía en los certámenes con los que se clausuraba el ciclo lectivo de los colegios y en los diversos actos públicos en los que pudieran llevarse a cabo rememoraciones exaltadas del pasado patrio.

El mismo método de preguntas y respuestas correspondientemente numeradas, fue el que usó José María Quijano Otero en la edición de su Compendio de Historia Patria por entregas en el periódico La Escuela Normal y en la primera edición de 1874 en libro. En este último se reprodujo casi el mismo texto del periódico, excepto las lecciones de la guerra de Independencia hasta el año de 1816, que suprimió, y la introducción que incluyó. Esta edición comprendió dos épocas: Conquista y Colonia (hasta el 20 de julio de 1810).

La segunda edición de 1883 sufrió modificaciones: añadió la Independencia hasta 1819 y la República con una cronología de los hechos hasta el año de 1863. Añadió además una advertencia que explicaba el sentido y los cambios introducidos en esta edición, entre ellos la supresión de los cuestionarios, por considerarlos pesados para los estudiantes, la inclusión de las fechas estrictamente necesarias y siempre relacionadas con un acontecimiento a tal punto de que "[...] quedará mejor guardado en la memoria del discípulo por la gloria que lo recuerda que por la raya que con lápiz ponga al margen [8...]"47. En esta edición los cuestionarios fueron reemplazados con indicaciones a los profesores responsables de llenar los vacíos ${ }^{48}$, quienes tendrían un libro de este tipo. En las notas de indicación a los profesores, Quijano Otero los invitaba a completar y amenizar las lecciones con pasajes como "[...] las hazañas de don Baltasar y la guerra de los Pijaos que pueden consultarse por extenso en la Historia del señor Groot"49, a señalar los yerros del libro y a enriquecer sus contenidos, haciendo llegar al autor nombres de mártires de la independencia olvidados, una manera de excitar "el patriotismo de cada cual de los maestros" ${ }^{50}$. Finalmente, incluyó el "Discurso sobre la historia colombiana" que había pronunciado en la Universidad Nacional y publicado en sus Anales en 1871 y que, un año después, en 1872 fue publicado como folleto en la imprenta de Echeverría Hermanos.

Lo libros de historia patria no debilitaron la oralidad, todo lo contrario, su lectura fue una práctica complementaria y fuertemente interrelacionada con aquella. En efecto,

\footnotetext{
${ }^{45}$ BNC, Fondo Pineda 748, pieza 6. Plaza, José Antonio de. Compendio, p. 25.

${ }^{46}$ Ibid., p. 23.

${ }^{47}$ Quijano Otero, José María. Compendio de historia patria (Bogotá: Imprenta de Medardo Rivas, 1883, 2ª edición).

${ }^{48}$ Ibid.

49 Ibid., p. 98.

50 Ibid., p. 261.
} 
los prólogos de estos libros señalan al maestro como un intermediario fundamental en la popularización de los contenidos; ellos podrían “[...] extender o amplificar a la voz esta rápida reseña que se hará aprender de memoria a los estudiantes" ${ }^{51}$. Del celo de los maestros para enseñar la gloria del pasado dependía, en gran medida, el éxito de la historia patria como saber memorioso para que "[...] aprendamos a hacer el sacrificio de la vida cuando sea necesario por la causa de la independencia, de la libertad i del pueblo"52.

La utilidad de la historia patria estribaba en la comprensión de la vida política como en una especie de estado onírico de guerra -la de un soldado ferviente de la causa patriótica-, que exigía a todo ciudadano la abnegación y el sacrificio, a la par que imponía "[...] pagar religiosamente las contribuciones establecidas por la ley"53, pero también un ciudadano comprometido con el mantenimiento de las instituciones. En síntesis, más que un saber compelido a la reflexión o a la crítica, la historia patria como versión memoriosa del pasado constituía un saber compartido y destinado a la configuración de una narración pretérita de gloria y sacrificio, que explicaba el presente y ayudaba a dibujar un porvenir de felicidad para todos.

Si bien afincado en un pasado común ya validado, ello no significa que se tratara de una visión cerrada, sesgada e inamovible del mismo; la historia patria se fue actualizando con las necesidades de la época, dilatando los contenidos para enseñar el pasado y el presente del país. Eso fue lo que pasó con la figura de Bolívar que, en los albores de la República y hasta más o menos 1872, era una personalidad discordante: para algunos era el libertador, mientras que otros lo acusaban de tirano, déspota, incapaz de anteponer los intereses de la república a los suyos ${ }^{54}$. Fue claramente en la década de 1880 en la que se exaltó a Bolívar como un prócer conciliatorio, de ello dan cuenta los festejos públicos llevados a cabo en 1884 con ocasión del primer centenario de su Independencia, y las páginas del Papel Periódico Ilustrado en el que se escribieron diversos textos para exaltar a Bolívar, no tanto en su faceta política, sino en la de militar libertador de la patria, así como en la publicación de grabados e ilustraciones tendientes a fortalecer el fervor encarnado en su figura, la misma que se trazaba más sobre el ideal de gran hombre modelado por la retórica, que por la exactitud fisonómica del retrato. Proceso

\footnotetext{
${ }_{51}$ Biblioteca Nacional de Colombia (BNC), Fondo Pineda 3, pieza 19. Pinzón, Cerbeleón. Catecismo Republicano, p. 12.

52 Ibid.

${ }^{53}$ Ibid.

${ }^{54}$ En artículo "Herencia que nos legó el difunto libertador" escrito por Florentino González, uno de los más fuertes detractores de Simón Bolívar, se lee: “¿De cuántos males políticos y morales no somos hoy deudores a Bolívar desde el aciago año de 1826? [...] Bolívar es, en fin, el que, disponiendo del país como de cosa propia, del tesoro público como de su patrimonio, y de las recompensas de la ley como dádivas de su voluntad, ha desmoralizado a los hombres, enseñándoles a quebrantar su palabra, a buscar fortuna en el crimen, y a ser hipócritas, falsos y dañinos. Esta es la positiva herencia que el Libertador ha legado, y contra la cual se tiene que luchar por muchos años, hasta extinguir el venenoso germen de la inmoralidad que emponzoña al Estado”. Periódico El Cachaco de Bogotá, núm. 1, Bogotá, 1 de agosto de 1833, p. 42.
} 
similar siguió la figura de Santander, que se fue incorporando en el panteón patrio hasta lograr ser completamente integrada en la faceta de hombre de las leyes hacia $1920^{55}$.

\section{Cambiar las armas por la pluma: escritores y patriotas}

Escribir un libro de historia patria fue desde 1850 una tarea capital a la que solamente podían dedicarse unos cuantos ciudadanos, reconocidos por su interés en el estudio del pasado y por sus calidades morales y políticas. Desde el punto de vista de la retórica, la autoridad no recaía exclusivamente en la sapiencia y erudición del escritor u orador, existían otras cualidades que robustecían la palabra y elevaban a su depositario frente a su auditorio. Para dirigirse a otros era indispensable poseer el cultivo de virtudes cívicas como amor a la justicia, al orden y a la patria y un desprecio por la opresión y la insolencia contra la mala fe y la corrupción ${ }^{56}$.

Las calidades morales enriquecían las intelectuales y eran descritas como "[...] un profundo conocimiento de la materia que tratas ${ }^{\$ 57}$ y cuya familiaridad se establecía con las "[...] ciencias para hermosear i amenizar con ellas tu asunto" ${ }^{58}$. Tales cuestiones interesan para entender quiénes eran y en razón de qué un escritor podía convertirse en una autoridad en materia histórica; para entender que esta forma del conocimiento en el siglo XIX no se producía de manera individual (era todo lo contrario), el trabajo de los historiadores como ya se decía, retomaba una serie de versiones, libros y hechos instituidos de antemano; también contaron con una documentación que, aunque incipientemente organizada, fue consultada y estudiada por los autores; por ejemplo José Antonio de Plaza afirmó que tuvo que "[...] reunir lo poco i mui diseminado que se encuentra en nuestros archivos" 59 . José María Quijano también consultó y coleccionó documentos que él mismo copió para su uso personal de los manuscritos guardados en la Biblioteca Nacional.

El párrafo anterior permite vincular a los escritores con tradiciones narrativas y documentales y entender que ellos canalizaron clamores e iniciativas sociales acerca de la importancia del estudio y la popularización del pasado patrio. Su relativo impacto no hubiera sido posible si no hubieran tenido prestigio moral gracias a sus valores cívicos y al saber histórico acumulado y valorado por sus coetáneos. Los historiadores simbolizaban la probidad, bajo la forma de la escritura del pasado como un servicio y una prueba de amor y lealtad a la patria, y su erudición e inteligencia por medio del estudio de libros y documentos del pasado de Colombia, que, mediante sus libros populares, llevaron al alcance de todos.

\footnotetext{
55 Ghotme Ghotme, Rafat Ahmed. "Santanderismo y antisantanderismo y la Academia de Historia: La operación histórica en el proceso de construcción de nación en Colombia 1910-1970", en Anuario Colombiano de Historia Social y de la Cultura, núm. 34, Bogotá, Universidad Nacional, Departamento de Historia, 2007, pp. 121-164.

${ }^{56}$ Sánchez, Francisco. Principios de retórica y poética (Madrid: Imprenta de Vallín, 1813), p. 125.

${ }^{57}$ Ibid., p. 125.

${ }^{58}$ Ibid.

${ }^{59}$ BNC, Fondo Arciniegas 10576. Plaza, José Antonio de, Memorias, “Introducción”.
} 
La probidad y la inteligencia eran cualidades que ayudaban a legitimar a sus poseedores como voceros del pasado y, a través del pasado, de las virtudes que debían prevalecer y los vicios a erradicar. La autoridad para dirigirse a otros se constituía en una especie de atribución socialmente conferida, sobre la base del saber intelectual, la personalidad intachable y los vínculos con el poder político. Valga señalar que la primera instancia de reconocimiento académico y moral era, justamente, la de los círculos de hombres de letras, el mismo que de diversos modos se prolongaba en los del poder político con el que se intersectaba e incluso se confundía, como bien lo afirma Malcom Deas ${ }^{60}$ " [...] las letras y el poder conformaban una esfera en la que el poder simbólico y político se fusionaban”.

Los vínculos políticos de estos autores pudieran hacer pensar que sus textos respondieron, exclusivamente, a formulaciones ideológicas y a demandas partidistas de la época en que fueron escritos. Es cierto que su cercanía posibilitó los contratos para su composición y las medidas para darlos a conocer a través de las adopciones y adaptaciones, o de incipientes mecanismos de publicidad, como anuncios, reseñas y recomendaciones. Sin embargo, los vínculos políticos no fueron condición preponderante para contratar un libro de historia patria. Cuando esta tarea se encomendó, se hizo con la convicción de que las personas que recibían esta responsabilidad poseían la formación intelectual, la experiencia en el dominio de la escritura y la corrección moral indispensable para llevarla a cabo.

Manuel Murillo Toro confió a Cerbeleón Pinzón (1813-1870) escribir el Catecismo Republicano por la reputación acumulada como profesor y abogado; dueño "[...] de una inteligencia lúcida y serena"61, con formación suficiente para "[...] vulgarizar lo más posible los principios de las ciencias morales y políticas, a fin de formar un pueblo republicano" ${ }^{62}$; un republicano que puso sus estudios, sus ideas y sus atributos morales en diversos textos, para que sirvieran a la patria mediante la formación de "[...] un pueblo que tuviese conciencia clara del derecho y del deber, y se hubiera familiarizado con ideas verdaderamente científicas" ${ }^{93}$.

José María Samper describió físicamente a Cerbeleón Pinzón, texto que muestra cómo las descripciones fisonómicas, más que ocuparse objetivamente de la apariencia de una persona, eran una convención para establecer analogías entre los rasgos físicos, las atribuciones morales, los vicios y las virtudes; la frente amplia, por ejemplo, "[...] denotaba una capacidad nada común, sin ningún signo de codicia, de ambición, de vanidad, ni de pasiones violentas ni mezquinas" ${ }^{64}$. A estas facultades morales se sumaba la pericia oratoria, habilidad altamente ponderada en una sociedad en la que

\footnotetext{
${ }^{60}$ Deas, Malcom. Del poder y la gramática y otros ensayos sobre historia, politica y literatura colombianas (Bogotá: Taurus, 2006).

${ }^{61}$ Samper, José María. "Cerbeleón Pinzón”, en Galería nacional de hombres ilustres o notables: o sea colección de bocetos biográficos (Bogotá: Imprenta de Zalamea, por F. Ferro, 1879), p. 348.

62 Ibid., p. 340.

${ }^{63}$ Ibid.

64 Ibid.
} 
la palabra dicha era una habilidad incuestionable para la vida pública en cualquiera de sus facetas, y una destreza imprescindible para aquellos que hicieran parte de los círculos letrados y que tuvieran conocimientos académicos.

Dirigirse a otros era realizar una autoridad socialmente conferida, que se desplegaba a través de recursos que, a pesar de su complejidad, se desarrollaban con una aparente simpleza. Cerbeleón Pinzón encarnaba muy bien la probidad y la autoridad que lo habilitaban a levantar su voz en los espacios públicos, ante auditorios conformados por personas de diversas clases sociales. Pinzón era, en palabras de Samper, un orador "[...] con la sencillez de quien tranquilamente sostiene una conferencia o conversación seria; y todos sus recursos se reducían al razonamiento sólido, las comparaciones oportunas, las imágenes más naturales" ${ }^{\prime 65}$.

Lo propio sucedió con José María Quijano, un historiador reconocido por regentar durante varios lustros la cátedra de Historia Patria en la Facultad de Letras y filosofía de la Universidad Nacional, a quien además adornaban cualidades de "orador fecundo y fácil, ameno escritor y de estilo propio" ${ }^{" 66}$. Físicamente se le describía con adjetivos que destacaban su caballerosidad y distinción: "[...] es alto de cuerpo, bien formado [...] ojos expresivos [...] y en todo se distingue por sus cultas maneras y afabilidad especial". ${ }^{67}$

Cuando en 1871 las directivas de la Universidad le subieron a Quijano Otero el sueldo anual a $\$ 600$, lo hicieron con el argumento de que era necesario "formar un texto para la enseñanza" ${ }^{68}$, razón por la cual el catedrático debería dedicarse con "[...] mayor consagración i más estudio que las cátedras comunes" ${ }^{69}$. Esta iniciativa pasó a ser disposición del gobierno de los Estados Unidos de Colombia; en septiembre de 1872 el escritor se comprometía a entregar diez pliegos impresos del Compendio de historia patria a la dirección de Instrucción pública a razón de $\$ 400^{70}$, texto que fue publicado por entregas en el periódico La Escuela Normal entre el tomo III, núm. 97 del 9 de noviembre de 1872 y el tomo V, núm. 207 de diciembre 19 de 1874 y con un total de 38 lecciones.

Del mismo compendio se publicaron tres ediciones en forma de libro; la primera (1874) contaba con 27 lecciones, dejando por fuera la Independencia (hasta 1816) que había incluido en la del periódico, y llegando solo hasta el 20 de julio de 1810. La segunda

\footnotetext{
${ }^{65}$ Ibid., p. 341

66 “Semblanza de José María Quijano”, en Papel Periódico Ilustrado, Bogotá, año II, núm. 25, Bogotá, Imprenta de Silvestre y compañía, 6 de agosto de 1882, p. 3.

67 Ibid.

68 "Decreto por el cual se incrementa el suelo al catedrático de Historia Patria de la Escuela de literatura y filosofía de la Universidad Nacional", en Anales de la Universidad, t. IV, Bogotá, núms. 37 y 38, enero y febrero de 1872, p. 38.

69 Ibíd.

${ }^{70}$ Archivo General de la Nación (AGN), Carta de José María Quijano a la Biblioteca Nacional, Ministerio de Gobierno, Sección Primera, Rollo 66, t. 65, f. 170v. (Bogotá, 9 de abril de 1860).
} 
edición, revisada y corregida por el autor, comprendía la totalidad de las épocas en las que se había periodizado la historia patria (Descubrimiento y Conquista, Colonia, Independencia y República), llegando hasta 1863, momento en el cual se crearon los Estados Unidos de Colombia, además de agregar un folleto llamado "Discurso sobre historia colombiana"71 que efectivamente había sido un discurso pronunciado por el autor ante sus estudiantes universitarios y que posteriormente salió en el periódico Anales de la Universidad, y luego en forma de folleto de la imprenta, de Echeverría Hermanos.

Estos autores reflejaban los alcances intelectuales que había logrado el país, su dedicación y ahínco al estudio de la historia patria dibujaban un derrotero del progreso expresado en el conocimiento del pasado, útil en la medida en que ayudaría a despejar y esbozar el porvenir y en el trabajo de inclusión de los sucesos patrios en los flujos de la historia del mundo civilizado. Estos hombres, depositarios de tradiciones narrativas y editoriales, eran, en virtud de su dedicación y entrega a la causa patriótica, soldados cuyas armas eran la pluma, el papel y las largas jornadas de trabajo con la finalidad de dar al país una visión gloriosa del pasado que coincidiera con las aspiraciones del porvenir. Bien se decía que el amor de José María Quijano por la patria era tal, que si "[...] hubiera nacido en la época de los grandes sacrificios habría ido con igual serenidad a los combates o al patíbulo"72. Su labor como divulgadores del pasado patrio no se restringía a la enseñanza fiel de los hechos, su labor rebasaba esta finalidad en el ideal de que sus enseñanzas sirvieran, sobre todo, para formar buenos ciudadanos, hombres de acción y soldados leales a la causa común de la defensa patria que incluía la libertad, el territorio y las instituciones.

\section{A modo de cierre}

Hace unos años con ocasión del Bicentenario de la Independencia se llevaron a cabo diversos eventos académicos que se preguntaban por su significación, por los sucesos y por su incidencia en la Colombia contemporánea. En el marco de aquella celebración en alguna región del país tuvo lugar un foro que se anunciaba como verdades y mentiras de la Independencia; el nombre me sonó sugestivo y muy problemático, pues planteaba - al modo de una polaridad absoluta- las narraciones dominantes en torno a los acontecimientos que dieron lugar a la nueva república casi como una denuncia acerca de la falacia de la historia republicana.

Lo problemático de aquel título, así los comentarios que se oyen sobre la enseñanza de la Historia como si se tratara de un aparato de tortura construido para ideologizar en función de unos grupos dominantes a toda una población presuntamente pasiva y vacía, dieron lugar a una serie de reflexiones, a través de las que se ha procurado entender no solo la Historia en el sentido del análisis histórico que se conoce hoy en el ámbito profesional, sino aquellas formas que a veces se confunden y se mezclan

\footnotetext{
${ }^{71}$ BNC, Fondo Cuervo 5019. Quijano Otero, José María. Discurso de la historia de Colombia (Bogotá: Imprenta de Echeverría Hermanos, 1871).

${ }^{72}$ Briceño, Manuel. "José María Quijano Otero", en Papel Periódico Ilustrado, año III, núm. 51, Bogotá, Imprenta de Silvestre y compañía, 30 de septiembre de 1883, p. 34.
} 
de manera indiscriminada, como si se tratara de un saber uniforme, eterno y con las mismas aspiraciones de verdad en todas las épocas y en todas las circunstancias.

Ver en detalle las particularidades del saber histórico, así como sus diversos avatares, requiere, además de un trabajo teórico, auscultar en las formas concretas con las cuales el conocimiento histórico se ha presentado en las sociedades, esto es, a través de las diversas manifestaciones tanto orales como escritas que se hayan podido tener. Por eso, antes que atender al análisis histórico desplegado en libros y revistas especializadas, tal cual se hace manifiesta hoy en una sociedad en la que la lectura es una práctica más o menos generalizada, y donde los textos escritos de historia se producen para públicos en su mayoría especializados, es necesario estudiar las manifestaciones seminales con las que el estudio del pasado se engarzó con la formación republicana, así como los formatos sobre los cuales se asentó una forma de entender el pasado y de darlo a conocer, una forma en la que todavía quedaban huellas de un mundo en el que la palabra dicha respondía a una concepción de verdad, y en la que la verdad misma era, en esencia, el producto de relaciones de una índole distinta a la a la que se conoce hoy; se refiere a una sociedad en la que palabra, memoria y verdad conformaban una tríada inseparable que definía el saber como repetición de lo ya conocido, antes que una indagación sometida al escrutinio de la observación y de la crítica, una sociedad en la que el arte de la palabra ocupaba un saber central en términos de la organización del pensamiento, así como de su formulación y elocución, y en la que todo conocimiento contaba con reglas precisas en cuanto a su belleza, corrección y precisión escrita y enunciativa.

Ahora, si bien es cierto que la historia desde el punto de vista del relato ha sido una herramienta poderosa para legitimar y auspiciar a los poderosos e imponer perspectivas que reivindican las gestiones de unos en detrimento de las de otros, y ha sido usada como una estrategia poderosa en la construcción de pasados recién inventados que validan situaciones a veces insostenibles, es tarea del historiador como analista develar las argucias del relato y mostrar en perspectiva los hechos de manera que puedan ser vistos en sus diversas facetas. Por otra parte, una pregunta por la historia patria de Colombia desde el análisis histórico ayuda a comprender y examinar los hilos con los cuales se han tejido las relaciones con la conciencia histórica; no deja de sorprenderme que los contenidos de historia patria sigan vigentes después de casi doscientos años, sin que se haya producido una reflexividad sistemática sobre el modo en el que se produjeron, sus mecanismos de canonización, los contextos mismos en los que fueron escritos y las orientaciones sociales que en el momento de producción incidieron en las interpretaciones.

Lo más próximo a un ejercicio de este tipo se ha dado por parte de quienes critican anacrónicamente estos textos, sin detenerse en sus condiciones de producción, señalando con cierta perspicacia que se trata de contenidos elitistas, excluyentes, cuando no conservadurizantes. No obstante, poco se han detenido en pensar las condiciones mismas en las que se hace la historia, en las que se configuran las interpretaciones y los relatos que le dan forma. Este punto supone una tarea crucial para todo historiador: pensar sobre el oficio, sus prácticas y sus incidencias sociales. Pensar el oficio implica 
un ejercicio que rebasa los asuntos temáticos y desplaza la atención hacia la conciencia histórica; aquí las repercusiones pasan de lo epistemológico a lo ontológico, ya que la pregunta deja de centrarse en lo acontecido (como conocimiento de un pasado que ya no puede modificarse), para plantear cómo se ha llegado a ser lo que somos, pregunta vital que anuda el pasado y el presente para explicar la existencia en su plenitud, no bajo el peso de un pasado yerto, que ya no se puede intervenir, sino en la idea de que el pasado será siempre una condición de posibilidad para comprender el presente.

\section{Bibliografía}

\section{Fuentes primarias}

\section{Archivos}

Archivo General de la Nación.

Archivos, Ministerio de Gobiernos, Sección primera.

Biblioteca Nacional de Colombia, Fondo Pineda.

Biblioteca Nacional de Colombia, Fondo Arciniegas.

Biblioteca Nacional de Colombia, Fondo Cuervo.

\section{Libros}

Acosta, Joaquín. Compendio del descubrimiento y colonización de la Nueva Granada en el siglo decimosexto. París: Imprenta de Beau, 1878.

Gómez Hermosilla, Josef. Arte de hablar en prosa y verso. Madrid: Imprenta Real, 1826.

Pinzón, Cerbeleón. Catecismo republicano para Instrucción popular, redactado a escitación del ciudadano presidente Manuel Murillo, destinándolo con especialidad a las escuelas de los cuerpos de guardia colombiana, creados por el decreto presidencial de $1^{\circ}$ de setiembre de 1864. Bogotá: Imprenta de El Mosaico, 1864.

Plaza, José Antonio de. Compendio de la historia de la Nueva Granada, desde antes del descubrimiento, hasta el 17 de noviembre de 1831. Para el uso de los Colejios nacionales $i$ particulares de la República, $i$ adoptado como testo de enseñanza por la Dirección jeneral de instrucción pública. Bogotá: Imprenta del Neogranadino, por León Echeverría, 1850. 
Plaza, José Antonio de. Memorias para la Historia de la Nueva Granada desde su descubrimiento hasta el 20 de julio de 1810. Bogotá: Imprenta del Neogranadino, por Ramón González, 1850.

Quijano Otero, José María. Compendio de historia patria para uso de las escuelas primarias. Bogotá: Imprenta de Medardo Rivas, 1ª edición en libro, 1874.

Quijano Otero, José María. Compendio de historia patria. Bogotá: Imprenta de Medardo Rivas, $2^{\text {a }}$ edición, 1883.

Quijano Otero, José María. Discurso sobre la historia de Colombia. Bogotá: Imprenta de Echeverría Hermanos, 1871.

Restrepo, José Manuel. Historia de la Revolución de Colombia en la América Meridional. París: Librería Americana, 1827.

Samper, José María. Galería nacional de hombres ilustres o notables: o sea colección de bocetos biográficos. Bogotá: Imprenta de Zalamea, por F. Ferro, 1879.

Sánchez, Francisco. Principios de retórica y poética. Madrid: Imprenta de Vallín, 1813.

\section{Publicaciones periódicas}

Briceño, Manuel. “José María Quijano Otero”, en Papel Periódico Ilustrado, Bogotá, año III, núm. 51, 30 de septiembre de 1883.

"Decreto por el cual se incrementa el sueldo al catedrático de Historia Patria de la Escuela de literatura y filosofía de la Universidad Nacional", en Anales de la Universidad, Bogotá, t. IV, núms. 37 y 38, enero y febrero de 1872.

"Decreto que organiza los colegios nacionales de la república", en Gaceta Oficial, año XIX, núm. 150, Bogotá, 1 de septiembre de 1850.

Kastos, Emiro, "Memorias para la historia de la Nueva Granada”, en El Neogranadino, año IV, núm. 144, Bogotá, 21 de febrero de 1851.

Ibáñez, Pedro M. “José Antonio de Plaza”, en Papel Periódico Ilustrado, año V, núm. 109, Bogotá, 1 de febrero de 1887.

Lleras, Martín, "Pedagogía”, en Escuela Normal, Periódico Oficial de Instrucción Pública, t. III, núm. 96, Bogotá, 26 de octubre de 1872.

García, Abraham, "Exámenes presentados por los alumnos de la Escuela Normal de Medellín”, en La Escuela Normal, Periódico Oficial de Instrucción Pública, t. III, núm. 101, Bogotá, 7 de diciembre de 1872. 
“Semblanza de José María Quijano”, en Papel Periódico Ilustrado, Bogotá, año II, núm. 25, 6 de agosto de 1882 .

\section{Fuentes secundarias}

\section{Libros}

Annino, Antonio y Rojas, Rafael. La Independencia: Los libros de la patria. México: Fondo de Cultura Económica, 2009.

Borda, José Joaquín. Historia de Colombia contada a los niños. Bogotá: Imprenta de El Mosaico, 1874.

Bourdieu, Pierre. ¿Qué significa hablar? Madrid: Akal, 2001.

Darnton, Robert. El negocio de la Ilustración. Historia editorial de la Encyclopedie 1775-1800. México: Fondo de Cultura Económica, 2006.

Deas, Malcom. Del poder y la gramática y otros ensayos sobre historia, politica y literatura colombianas. Bogotá: Taurus, 2006.

Goody, Jack (comp.). Cultura escrita en sociedades tradicionales. Barcelona: Gedisa, 2003.

Havelock, Eric. Prefacio a Platón. Madrid: Visor, 1994.

MacKenzie, Donald Francis. Bibliografía y sociología de los textos. Madrid: Akal, 2005.

Ong, Walter. Oralidad y escritura, tecnologías de la palabra. México: Fondo de Cultura Económica, 2009.

Ricœur, Paul. Tiempo y narración III. El tiempo Narrado. México: Siglo XXI, 1996.

\section{Artículos de revistas}

Gothme, Rafat Ahmed. "Santanderismo y antisantanderismo y la Academia de Historia: La operación histórica en el proceso de construcción de nación en Colombia 1910-1970”, en Anuario Colombiano de Historia Social y de la Cultura, núm. 34, Bogotá, 2007.

López Lopera, Liliana. "Figuraciones de la tierra natal: patria nación y república”, en Co-herencia, vol. XI, núm. 21, Medellín, 2014. 
Murilo de Carvalho, José. "Historia intelectual: la retórica como clave de lectura", en Prismas: revista de historia intelectual, núm. 2, 1998.

Navarro Antonín, Fernando. "La retórica del discurso: La cohortatio: tradición clásica y pervivencia”, en Cuadernos de filología clásica y estudios latinos, núm. 19, Madrid, 2000 .

Silva, Renán. "El sermón como forma de comunicación y como estrategia de movilización en el Nuevo Reino de Granada a principios del siglo XVIII", en Revista Sociedad y Economía, núm. 1, 2001. 